\title{
OPINION
}

\section{Promoting Mental Health for healthier subsistence}

\author{
Upadhya KD* \\ Consultant Psychiatrist Kathmandu Model Hospital \& Advisor, Community Mental health and \\ Counseling (CMC-N) Nepal.
}

E-mail *Corresponding author: kapil.upadhyaya@yahoo.in

\begin{abstract}
Mental health is not merely an absence of mental illness. It's also a relationship between an individual and the society that the individual dwells and all the social process and institutions that a society embodies within.

There exist several personal and environmental factors culminating into some form of mental illness. Therefore prevention of these factors helps prevent mental illness or delay their onset for timely intervention. Various public health strategies have genuine implications in day to day life an individual and population at large. The combination of mental health with such public health strategies will have synergistic effect.
\end{abstract}

Key words: Mental health, Mental Health promotion, Evidence based intervention in mental health

\section{INTRODUCTION}

$\mathrm{W}$ orld Health Organization defines health promotion as "the process of enabling people to increase control over and to improve their health". ${ }^{1}$ Mental health promotion often refers to positive mental health, rather than mental ill health. Positive mental health is the desired outcome of health promotion intervention. Commonwealth Department of Health and Age Care defines mental health promotion as " any action taken to maximize mental health and well being among populations and individuals". ${ }^{2}$ Hodgson et al. defined mental health promotion as the enhancement of the capacity of individuals, families, groups or communities to strengthen or support positive emotional, cognitive and related experience. ${ }^{3}$

Mental health promotion applies to the whole population in the context of everyday life. Positive mental health is the result of many interacting factors, so there is no single way to napromote it. Communities are made up of a diverse range of people, so mental health promotion need to consider a variety of strategies and approaches that are relevant to all these people of different backgrounds.
The determinants of mental health include not only factors related to actions by individuals, such as behaviors and lifestyles, coping skills, and good interpersonal relationship, but also social and environmental factors like income, social status, education, employment, housing and working conditions, access to appropriate health services, and good physical health. ${ }^{4}$

\section{RISK FACTORS OF MENTAL ILLNESS}

When we talk about prevention of mental disorders, we have to know the risk factors which cause mental disorders. Risk factors can mainly be divided into two groups: personal and environmental. The personal risk factors mainly include genetic, neurotransmitters, endocrine system and the hormones. We generally have no control on genetic factors and neurotransmitters, but healthy life styles and proper management of stress may prevent or at least delay the onset of mental disorder.

Environmental factors like poverty, unemployment, low education, deprivation and homelessness, alcohol and drug use 
problems, malnutrition, stigma of illness, and head injuries are some of the common causes leading to mental disorders. Prevention of these factors can also prevent some mental disorders and also the physical illnesses. Parental deprivation under 5 years of age, lack of consistent rules in the family, physical and emotional abuse of children, poor school environment, peer group pressure and cumulative stress can lead to mental disorder. Conflicts, trauma, and torture can lead to mental disorder which is often long lasting and difficult to treat. Prevention of these factors can prevent many mental disorders.

\section{EVIDENCE - BASED INTERVENTIONS}

- Perinatal and postnatal visits by nurses and community workers to mothers to prevent poor child care, child abuse, postnatal depression and improve childparent attachment and good parenting skills. The reported mental health related outcomes were reduced smoking and better social support for mothers and reduced child abuse and better educational achievement in the children.5,6

- Breast-feeding is supposed to improve bonding and attachment between the infant and mother. Breast-feeding also has significant benefit to child development. ${ }^{7}$

- Iodine deficiency is the most common cause of preventable brain damage. 8,9 Cretinism is a known detrimental effect of iodine deficiency. Studies have revealed that iodine deficiency affects the intelligence level of even the apparently healthy population living in an iodine deficient area. ${ }^{10}$ Use of only iodized salt has helped to prevent iodine deficiency in children.

- Alcohol abuse during pregnancy has been associated with low birth weight babies, foetal alcohol syndrome and other intellectual disabilities in the babies. ${ }^{11}$

- It is possible to improve self esteem and life skills through pro-social behaviour, school-based curricula and improvement of school climate. ${ }^{12}$
- Studies have shown that it is possible to prevent suicide through a comprehensive school-based prevention program. In a 5 year longitudinal study done in Miami, 330000 public school children and adolescents were selected. A comprehensive strategy aimed at reduction of suicide was developed. It included components to modify school policy, provided teachers training, parent education, stress management and life skills curriculum and introduced a crisis team in each school. The result showed $63 \%$ reduction in suicide rates and $64 \%$ reduction in suicide attempts. ${ }^{13}$

- Reducing alcohol consumption and smoking in youth through intervention during the early elementary and middle school years had been found to be effective in the adolescent Alcohol Prevention Trial. ${ }^{14}$

- Life skills training has been found to enhance self-efficacy and to prevent substance abuse and behavioural problems and WHO has promoted life skills training in schools. ${ }^{15}$

- Brief physician advice and other forms of brief interventions have been found to be effective in reducing alcohol use in the WHO Project on identification and management of alcohol-related problems. ${ }^{16}$

- Depression and schizophrenia account for the majority of suicides due to psychiatric disorders. Suicide prevention through the prescription of antidepressant and antipsychotic drugs to individuals with mental disorders can thus be of benefit. ${ }^{17}$

- Prevention and management of posttraumatic stress disorder through a short cognitive behavioural program among victims of vehicular and industrial accidents have been found to be beneficial. ${ }^{18,19}$

- Legislation for wearing helmets and seat belts are promoted in order to reduce head injuries and other physical injuries that may lead to mental disorders and disabilities. ${ }^{20}$ 


\section{PREVENTIVE AND PROMOTIVE ASPECT OF MENTAL HEALTH}

In a country like Nepal, where basic mental health service is not available to a large number of underserved people, talking of prevention and promotion of mental health may seem irrelevant at this stage. However treatment of mental disorders, prevention and promotion of mental health are interrelated and they can go side by side.

Education, employment, social well-being, availability of food, housing and other public health related factors play an important role in preventing mental disorders and promoting mental health. These factors are also important for good physical health. Combining prevention and promotion programs in mental health within overall public health strategies reduce stigma, increase cost effectiveness, and provides multiple positive outcomes.

Everyone wants to be happy and live a productive life. But every one of us has to face problems, failures, difficulties and crisis in our life. We all want happy married life, good care of our children, maintain friendship and good health. But a dilemma arises between whether we are really trying to achieve these goals or these are just our wishful desires. Promotion of mental health deals with problem solving skills, capacity building skills, stress management skills and dealing with ourselves and others.

\section{REFERENCE}

1. World Health Organization. Ottawa Charter for Health Promotion. Geneva, 1986.

2. Commonwealth Department of Health and Aged Care. Introduction. In: Promotion, prevention and early intervention for mental health- a monograph. Canberra, Mental Health and Special Programs Branch, Commonwealth Department of Health and aged care, 2000: 1-8.

3. Hodgson R, Abbasi T, Clarkson J. Effective mental health promotion: a literature review. Health education Journal, 1996; 55:55-74.
4. 4.Herrman $H$. The need for mental health promotion. Australian and NewZealand Journal of Psychiatry, 2001;35:709-715.

5. Olds DL, Handersson CR, Tatelbaun R, Chamberlin R. Preventing child abuse and neglect: A randomized trial of nurse home visitation. Paediatrics, 1986; 78:6578.

6. Olds DL, Handersson CR, Tatelbaun R, Chamberlin R. Improving the life-course development of socially disadvantaged mothers: a randomized trial of nurse home visitation. American Journal of Public Health, 1988; 78: 1436-1444.

7. Quinn PJ, O'Callaghan M, Williams GM, Najman JM, Andersen MJ, Bor W. The effect of breast-feeding on child development at 5 years: a cohort study. Journal of Paediatrics and Child Health, 2001; 37:465-469.

8. Hetzel BS. Eliminating iodine deficiency disorders - the role of the International Council in the global partnership. Bulletin of the World health Organization

9. Hetzel BS, Dunn JT, Stanbury JB. The prevention and control of iodine deficiency disorders. Amsterdam, New York, Oxford, Elsevier, 1987.

10. Bleichrodt N, Born MP. A meta-analysis of research on iodine and its relationship to cognitive development. In JB. Stanbury, ed. The damaged brain of iodine deficiency. New York, Cognizant Communication Corporation, 1994:195200.

11. Floyd RL, Decoufle P, Hungerford DW. Alcohol use prior to pregnancy recognition. American Journal of Preventive Medicine, 1999, 17:101-107

12. Schweinhart LJ,Weikart DP. High/Scope Perry Preschool Program outcomes. In: McCord J, Tremblay RE,eds. Preventing antisocial behaviour: intervention from birth through adolescence. New York, Guiford Press, 1992:67-86.

13.Zenere FJ $3^{\text {rd }}$, Lazarus PJ. The decline of youth suicidal behaviour in an urban, multicultural public school system following the introduction of a suicide prevention and intervention program. Suicide \& Life- Threatening Behavior, 1997; 27:387-402 
14. Hansen WB, Graham JW. Preventing alcohol,Mrijuana and cigarette use among adolescents: peer pressure resistance training versus establishing conservative norms. Preventive Medicine, 1991; 20:414-430.

15. World Health Organization. Life Skills education in schools. Geneva, 1993. WHO/MNH/PSF/93.7A.Rev.2.

16. Babor TF, Grant M. Project on identification and management of alcohol-related problems. Report on phase II: A randomized clinical trial of brief interventions in Primary health care. Geneva, World Health Organization, 1992.

17. Roy A. Suicide.In: BJ Sadock and VA Sadock, eds. Comprehensive Textbook of Psychiatry. Philadelphia, Lippincott Williams \& Wilkins, 2000: 2031-2040.

18. Fecteau G. Nicki R. Cognitive behavioural treatment of post-traumatic stress disorder after motor vehicle accident. Behavioural \& Cognitive Psychotherapy, 1999; 27:201-214.

19. Bryant RA. Harvey AG. Dang ST. Sakville T. Basten C. Treatment of acute stress disorder: a comparison of cognitive behavioural therapy and supportive counseling. Journal of Consulting \& Clinical Psychology, 1998; 66:862-866.

20. Cameron MH. Vulcan AP. Finch CF. Newstead SV. Mandatory bicycle helmet use following a decade of helmet promotion in Victoria, Australia- an evaluation. Accident analysis \& prevention, 1994; 26:325-37. 